\title{
Odontoma-Like Malformation: Sequlae of Trauma in The Primary Dentition: Case Report
}

\begin{abstract}
Yamina Elelmi ${ }^{1}$, Faten Khanfir $^{2}$, Fatma Masmoudi ${ }^{1}$, Ahlem Baaziz ${ }^{1}$, Faten Ben Abdallah ${ }^{2}$, Fethi Maatouk ${ }^{1}$, Hichem Ghédira ${ }^{1}$
${ }^{1}$ Pediatric Dentistry Department, Faculty of Dental Medicine, Dento-Facial Biological and Clinical Approach Laboratory, LR12ES10, 5000, Monastir, Tunisia

${ }^{2}$ Department of Anatomy, Faculty of Dental Medicine; 5000, Monastir, Tunisia

\author{
Received: 19.08.2020 \\ Published: 12.10 .2020
}

Article History

Accepted: 22.09 .2020

Journal homepage:

https://www.easpublisher.com/easjdom

Abstract: Traumatic injury to the primary teeth can cause significant alteration of the underlying permanent dentition because of the close anatomic relationship between the developing permanent teeth and the apices of the overlying primary incisors. Aim: This case report describes a rare complication of odontoma -like malforamtion along of the permanent tooth, resulting from the intrusion of the predecessors at very young age.Clinical and radiographic examination revealed unerupted left maxillary central incisor blocked by a compound odontoma.The treatment plan was the surgical removal of the odontoma. Clinical and radiological follow-ups have been established to monitor the eruption of the permanent tooth.

Keywords: Odontoma like malformation, Intrusive injury, Treatment, Trauma.
\end{abstract}

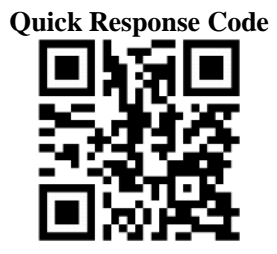

Copyright $\odot 2020$ The Author(s): This is an open-access article distributed under the terms of the Creative Commons Attribution 4.0 International License (CC BY-NC 4.0) which permits unrestricted use, distribution, and reproduction in any medium for non-commercial use provided the original author and source are credited.

\section{INTRODUCTION}

Traumatic dental injuries are relatively common among children. Studies have shown that approximately $30 \%$ of the children had sustained dental trauma at the age of 7 years[1,2].

The most serious injuries to primary teeth occur between the ages of 1 and 3 years [3]. The majority of the trauma occurs as a result of fall accidents at home [4].

The highly resilient and flexible supporting structures result in luxation injuries rather than fractures of the teeth. These luxation injuries constitutes 62 to $73 \%$ of all injuries to the primary dentition of which intrusive and extrusive traumas are more common than other luxation injuries [3]. Developmental disturbances of permanent successors are often seen as a result of the intrusion of primary incisor.

The close relationship between the apices of the primary teeth and the developing permanent successors explains the high prevalence of disturbances that include hypoplastic defects, root dilacerations, and other enamel or developmental disturbances that are not seen until months or years after the injury when the permanent successors erupt $[5,6]$.

The sequelae and their gravity depend on the age of the occurring of the traumatism, the intensity and the direction of the shock.

The objective of this article was to describe through a clinical case the diagnostic elements and the management of odontoma-like malforamtion resulting from intrusive injury at very young age

\section{Case Report}

A 8 years old boy consulted the Department of Pediatric Dentistry and Prevention of the Dental Clinic of Monastir, Tunisia with the complaint of unerupted left permanent maxillary central incisor(21).Anamnesis reported history of trauma at the age of 2 years, leading to the intrusion of the 61 , without any dental follow up.

The clinical examination revealed mixed dentition and the presence of the right permanent central incisors (11). The left permanent central incisor was missing (21). (figure 1) 


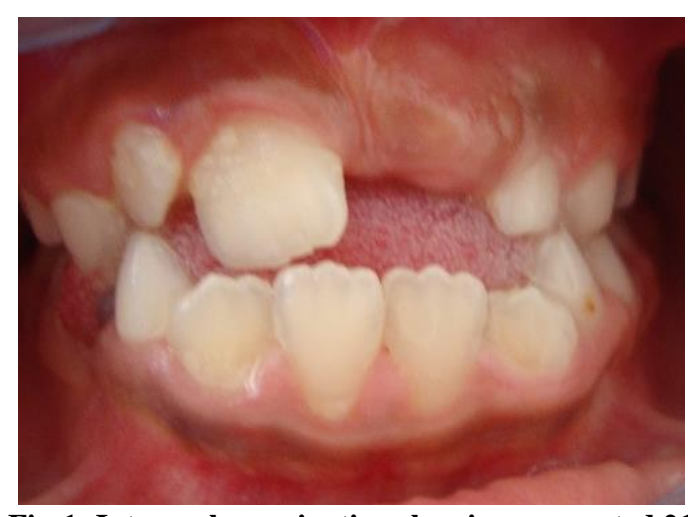

Fig-1: Intraoral examination showing unerupted 21

Panoramic radiograph showed an impacted permanent left maxillary central incisor and multiple radiopaque structures. The crown of the lateral incisor(22) appears to be malformed (figure 2).

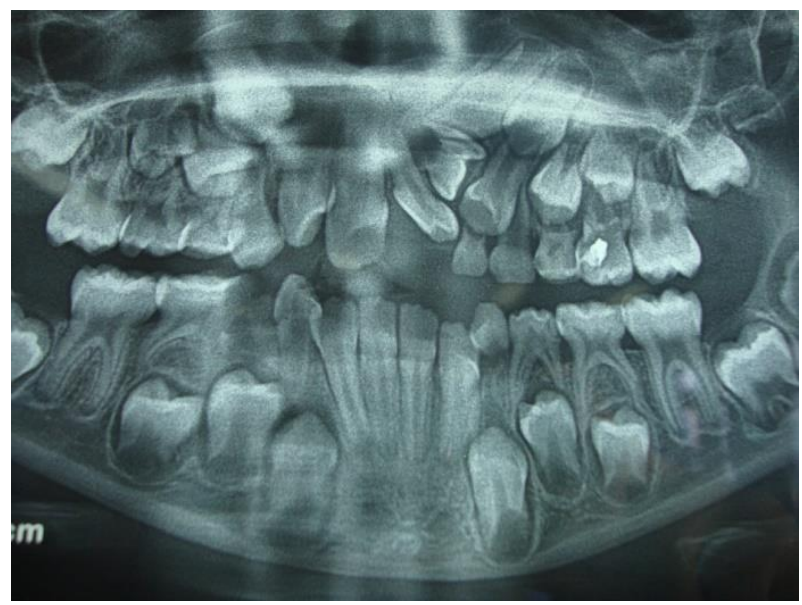

Fig-2: Panoramic radiograph showing impacted permanent left maxillary central incisor and multiple radipaque structures

Based on clinical and radiographic examination the final diagnosis was an odontoma-like malformation caused by trauma inflicted to the primary dentition.

The treatment plan was the surgical removal of the compound odontoma under local anaesthesia. (Figure 3).

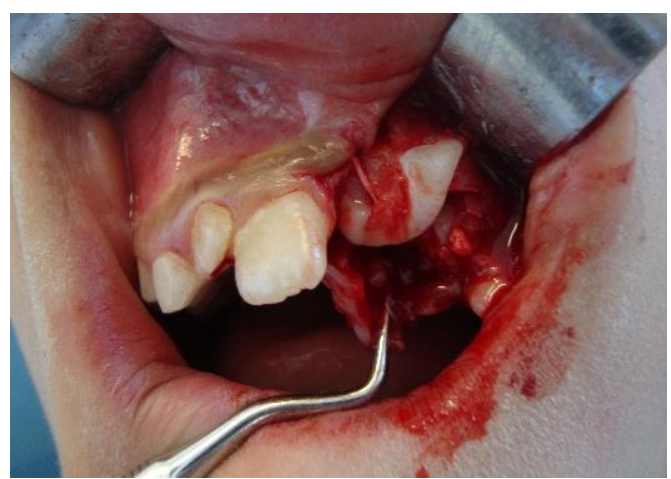

Fig-3: Removal of the compound odontoma
Compound odontome was removed (figure 4) and the flap was sutured(figure 5)

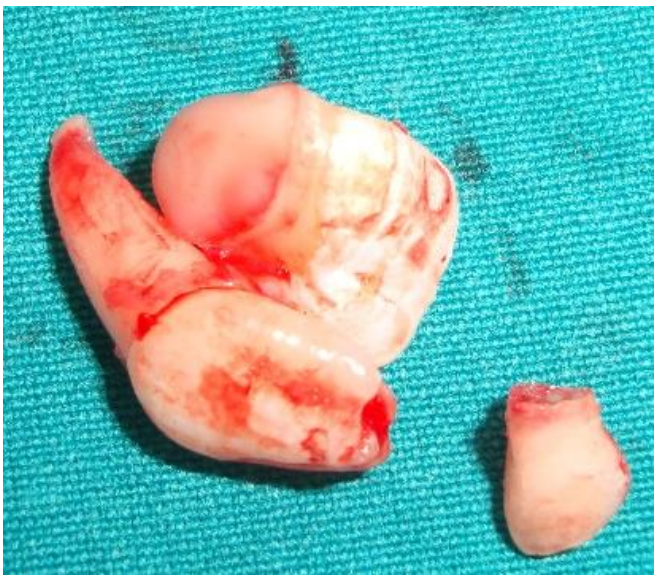

Fig-4: Compound odontome

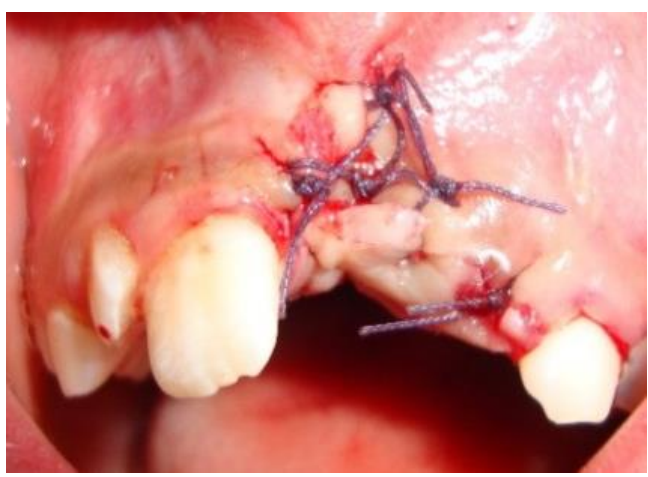

Fig-5: Sutured flap

Histopathologic examination of the hard tissue specimen confirmed the diagnosis of compound odontome. Partial denture was considered until the eruption of the impacted tooth. Clinical and radiological follow-ups were established to monitor the eruption the permanent incisor.

\section{DISCUSSION}

During the initial growing period of a child when motor coordination is not well developed, the incidence of trauma to the primary dentition is greatest[7].

When trauma occurs during the stage of odontogenesis, it can seriously affect the morphogenetic stages of tooth development [8]. The prevalence of developmental disturbances secondary to dental injuries in the primary dentition ranges from $12 \%$ to $69 \%$ [9].

The severity and the extent of the disturbances depends on the intensity and the direction of the impact on the primary teeth, and the stage of germ development(the child's age at the time of the injury). Intrusion and avulsion injuries result in the highest risk of causing developmental disturbances $[10,11]$. 
The majority of traumatic injuries occur at age 2 years, during the developmental stage of the permanent crown $[12,13]$. Depending on the severity of the trauma and on the stage of tooth morphogenesis, the alteration could result in specific malformations, such as enamel hypoplasia, root and crown dilacerations, and less frequently, odontoma. Odontogenic tumors, as odontoma, are rare with an absolute incidence from $0.002 \%$ to $0.1 \%[14,15]$.

Odontoma-like malformations are rare complications developed after trauma, confined primarily to maxillary incisors, when the time of injury occurs between ages $<1$ and 3 years during the morphogenetic stages of the dental follicle and results mainly from intrusive luxation or avulsion. It is a mass of mineralized tissue slightly similar to the dental germ and may have a relatively normal or rudimentary root and occur during early phases of odontogenesis [7, 12].

In our case, the trauma occurred at the age of 2 years leading to odontoma-like malformation. The period between 0 and 3 years of age corresponds to the development and mineralization of the crown (Nolla's stage $4,2 / 3$ of the formed crown $[10,12]$.

According to Andreasen [1] the younger the child is at the time of injury, between 1 and 4, the more severe are the developmental disturbances involving the crown of the successor, corresponding to Nolla's stages 1-5 [16]. The sequelae in the root formation occurs more commonly when the trauma afflicts children more than 4 years old, at a time when the crown of the successor is in its final stage of formation and the root initiating the developing process, starting the dental development Nolla's stage 6[16].

These sequelae require multidisciplinary approach.The surgical removal of the odntome, for this case, was planned to allow the eruption of the 21

\section{Conclusion}

The traumatic injuries on the deciduous teeth can affect the germ of the successor in development.Thus, regular follow-up and radiographs are recommended in cases of intrusion injuries in children 1-3 years of age to allow early detection and management of possible developmental disturbances.

\section{REFERENCES}

1. Andreasen, J.O., Ravn, J.J. (1971). The effect of traumatic injuries to primary teeth on their permanent successors. II. A clinical and radiographic follow-up study of 213 teeth. Scand $J$ Dent Res, 79: 284-94.
2. Borum, M.K., Andreasen, J.O. (1998). Sequelae of trauma to primary maxillary incisors. I. Complications in the primary dentition. Endod Dent Traumatol, 14:31-44.

3. Rocha, M.J., Cardoso, M. (2007). Survival analysis of endodontically treated traumatized primary teeth. Dent Traumatol, 23: 340-7.

4. Bastone, E.B., Freer, T.J., McNamara, J.R. (2000). Epidemiology of dental trauma: a review of the literature. Aust Dent J, 45:2-9.

5. Ravn, J.J. (1976). Developmental disturbances in permanent teeth after intrusion of their primary predecessors. Scand J Dent Res, 84(3):137-141.

6. Canoglu, E., Akcan, C.A., Baharoglu, E., Gungor, H.C., Cehreli, Z.C. (2008). Unusual ectopic eruption of a permanent central incisor following an intrusion injury to the primary tooth. J Can Dent Assoc, 74(8):723-726.

7. Andreasen, J.O., Ravn, J.J. (1972). Epidemiology of traumatic dental injuries to primary and permanent teeth in a Danish population sample. Int J Oral Surg, 1: 235-9.

8. Diab, M., elBadrawy, H.E. (2000). Intrusion injuries of primary incisors. Part III: effects on the permanent successors. Quintessence Int, 31:37784.

9. Brin, I., Fuks, A., Ben-Bassat, Y., Zilberman, Y. (1984). Trauma to the primary incisors and its effect on the permanent successors. Pediatr Dent, 6:78-82.

10. Von, Arx, T. (1993). Developmental disturbances of permanent teeth following trauma to the primary dentition. Aust Dent J, 38:1-10.

11. Ben-Bassat, Y., Brin, I., Zilberman, Y. (1989). Effects of trauma to the primary incisors on their permanent successors: multidisciplinary treatment. ASDC J Dent Child, 56:112-6.

12. Arenas, M., Barbería, E., Lucavechi, T., \& Maroto, M. (2006). Severe trauma in the primary dentitiondiagnosis and treatment of sequelae in permanent dentition. Dental Traumatology, 22(4), 226-230.

13. Sennhenn-Kirchner, S., \& Jacobs, H. G. (2006). Traumatic injuries to the primary dentition and effects on the permanent successors-a clinical follow-up study. Dental Traumatology, 22(5), 237241.

14. d'Oliveira, B. H., Campos, V., \& Marçal, S. (2001). Compound odontoma-diagnosis and treatment: three case reports. Pediatric dentistry, 23(2), 151-157.

15. Stajcic, Z. Z. (1988). Odontoma associated with a primary tooth. The Journal of pedodontics, 12(4), 415.

16. Nelson-Filho, P., Silva, R. A., Faria, G., \& de Freitas, A. C. (2005). Odontoma-like malformation in a permanent maxillary central incisor subsequent to trauma to the incisor predecessor. Dental Traumatology, 21(5), 309-312. 